\title{
Management of Idiopathic Unilateral Plantar Fasciitis
}

\author{
Dr. Milind Deshpande ${ }^{1}$, Dr. Cleofina Furtado ${ }^{2}$ \\ ${ }^{1}$ Lecturer, Department of Orthopaedics, Goa Medical College, Bambolim, Goa, India \\ ${ }^{2}$ Post Graduate, Goa Medical College, Bambolim, Goa, India
}

\begin{abstract}
A review of 121 patients of idiopathic unilateral plantar fasciitis treated with two different methods of conservative therapy is being reported here. The purpose of the study was to assess the effectiveness of the two different methods of treatment.

The first method of treatment involved treatment with

1. Oral tablets of calcium carbonate with cholecalciferol 250 IU once a day for 3 months.

2. Tablet of Vitamin D3 60000 IU given once a week for 3 months.

3. Silicone insoles inside the footwear.

4. Vegetarian diet.

5. Specific plantar fascia stretch exercises, General exercises - like walking, yoga etc. whichever the patient was doing regularly.

6. Hot water fomentation for 5 minutes by dipping the leg, ankle deep, in a bucket of warm water once daily.
\end{abstract}

The second method of treatment involved treatment with

1. Oral tablets of calcium carbonate with cholecalciferol 250 IU once a day for 3 months.

2. Tablet of Vitamin D3 60000 IU given once a week for 3 months.

3. Microcellular rubber insoles inside the footwear

4. No dietary restrictions

5. General exercises - like walking, yoga etc. whichever patient was doing regularly and no specific plantar fascia stretch exercises taught.

6. Ice applications - ice cubes from refrigerator used to foment the painful area for 5 minutes once daily.

The heel pain subsided in $84.90 \%$ cases slowly and steadily over a period of 6 months with the first method of treatment while it subsided only in $52 \%$ cases with the second method of treatment.

Keywords: Plantar fasciitis, Conservative

\section{Introduction}

Plantar fasciitis occurs in trained as well as non-trained workers, though more common in athletes $(1,2)$. It is known to affect approximately 1 million persons per year, and two-thirds of patients with plantar fasciitis will seek care from their family physician and one third to orthopaedic surgeon $(3,4)$

Plantar fasciitis is caused either due to degenerating process, hard footwear, local and systemic diseases, trauma or is idiopathic. Pathological findings involve myxoid degeneration with fragmentation and degeneration of the plantar fascia and bone marrow vascular ectasia without any signs of inflammation (5). Approximately $15 \%$ of all adult foot complaints are due to this disorder (6). Some have reported the cause as an excessive amount and/or a prolonged duration of pronation resulting in structural strain and plantar fasciitis $(7,8)$. Others have reported weight gain, occupation-related activity, anatomical variations, poor biomechanics, overexertion, and inadequate footwear as contributing factors (8-10). However, the exact cause is yet to be found and is probably multifactorial.

The patient presents with classical pain more on the medial aspect of calcaneus on the sole of the feet when he or her first stands on the feet on waking up in the morning and which aggravates on doing the day to day activities $(9,11$, 12). The first step after every sitting or sleeping pause is an alarming reminder of the problem to the patient. Radiologic $\mathrm{x}$ ray might show a heel spur on the inferior surface of the calcaneum (13). However, the radiographic finding is rarely used in diagnosis and diagnosis relies more on history and physical examination, which shows localized tenderness on anterior-medial aspect of the calcaneus aggravated by passive dorsiflexion of the toes or standing on the tips of the toes $(9,11)$.

Non-surgical conservative treatment is found to be more efficacious and potent than the inflammatory or surgical methods in almost $90 \%$ of patients and surgical treatment is reserved for persistent, severe symptoms refractory to nonsurgical intervention for at least 6 to 12 months $(7,12$, 14-16). In contrast there have been data that proves nonsurgical conservative treatment to be ineffective (17), and thus there exist controversies in the modalities of treatment of plantar fasciitis.

The aim of this study was to find which conservative method is more productive than the other. Two methods of conservative treatment were compared for their effectiveness in treating idiopathic unilateral plantar fasciitis. 


\title{
International Journal of Science and Research (IJSR) \\ ISSN (Online): 2319-7064
}

Index Copernicus Value (2016): 79.57 | Impact Factor (2015): 6.391

\section{Methodology}

121 patients ( 83 males and 38 females) in the age group of 42-57 years were treated. 64 patients (43 male and 21 female) were treated with first method and the remaining 57 patients (40 male and 17 female) with second method of treatment. All patients were treated at the outpatient department of Orthopaedics at Goa Medical College, Bambolim, Goa. It was an open label study design. Patients were given the choice to select between the two methods of conservative treatment. Patient's written consent was taken to undergo the study.

Only patients whose cause of unilateral heel pain could not be assigned to any cause were labeled to be suffering from idiopathic plantar fasciitis and were involved in the study. They underwent investigations like blood pressure (BP) measurement, fasting blood sugar level (FBSL), serum creatinine, serum uric acid, hemoglobincount $(\mathrm{Hb})$, total WBC count (TC), differential WBC count (DC), erythrocyte sedimentation rate (ESR), rheumatoid factor (RA) and a radiograph of the affected ankle. The above tests were normal in all cases and none had received any previous treatment.

Inclusion criteria:

1. Unilateral idiopathic plantar fasciitis

2. Age group: 42 to 57 years

3. Mixed diet pattern

4. Heel pain for a minimum period of six weeks.

Exclusion criteria:

Bilateral plantar fasciitis

Age group: Less than 42 years and more than 57 years

Exclusive vegetarian or non-vegetarian diet pattern

Heel pain for less than six weeks.

The first method of treatment involved treatment with

1. Oral tablets of calcium carbonate with cholecalciferol $250 \mathrm{IU}$ once a day for 3 months.

2. Tablet of Vitamin D3 60000 IU given once a week for 3 months.

3. Silicone insoles inside the footwear.

4. Vegetarian diet.

5. Specific plantar fascia stretch exercises. General exercises - like walking, yoga etc. whichever the patient was doing regularly.

6. Hot water fomentation for 5 minutes by dipping the leg, ankle deep, in a bucket of warm water once daily.

The second method of treatment involved treatment with

1. Oral tablets of calcium carbonate with cholecalciferol 250 IU once a day for 3 months.

2. Tablet of Vitamin D3 60000 IU given once a week for 3 months.

3. Microcellular rubber insoles inside the footwear

4. No dietary restrictions
5. General exercises - like walking, yoga etc. whichever patient was doing regularly, and no specific plantar fascia stretch exercises taught.

6. Ice applications - ice cubes from refrigerator used to foment the painful area for 5 minutes once daily.

The assessment of pain relief was done by a Numerical pain rating scale (NPRS) supplemented with a faces pain scale (FPS) for self-reported pain intensity at 1, 2, 3 and 6 months of follow up (36).

Participants were provided a full explanation of the NPRSFPS, which combined a vertical NPRS and the 6-face Wong-Baker FPS, and were instructed on how to complete the assessment. The NPRS-FPS was a combination of the vertical NPRS with word anchors on a scale from 0 to 10 and the 6 facial expressions of the FPS, facilitating scoring of the intensity of participants' pain (Fig. 1).

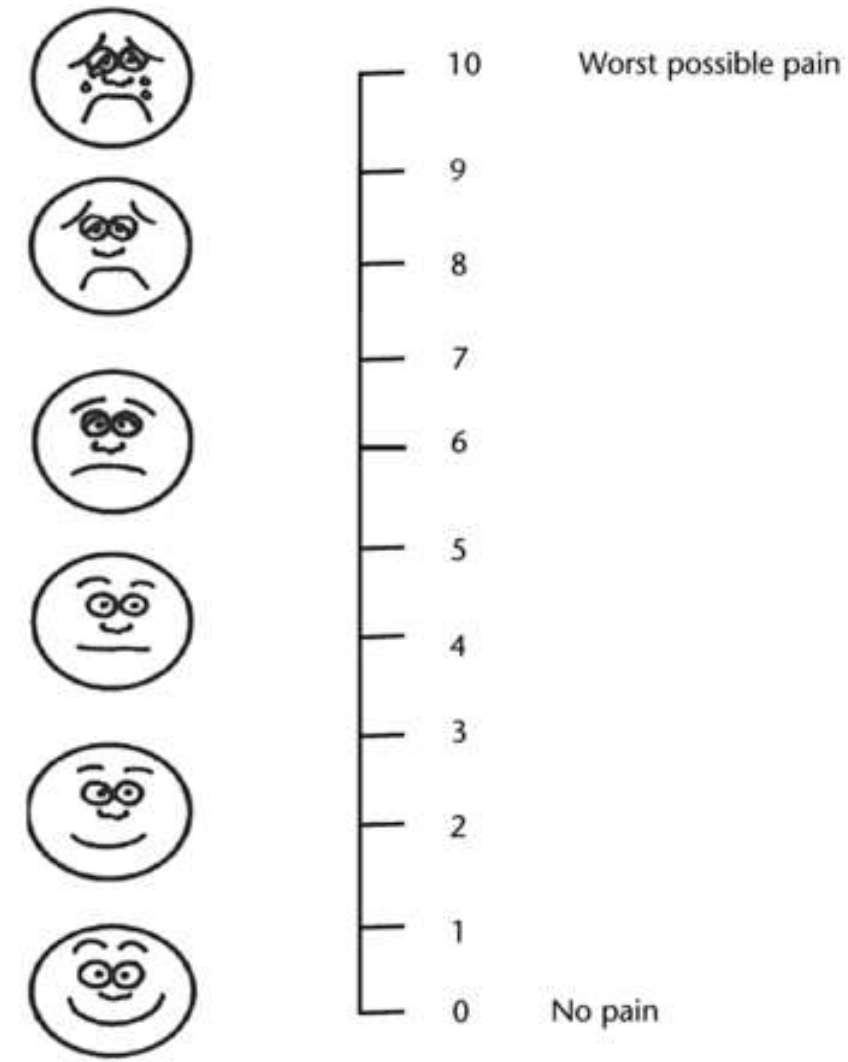

Figure 1

Numerical pain rating scale supplemented with a faces pain scale for self-reported pain intensity.

The NPRS consisted of a 100-mm vertical line numbered with 0 as the bottom number to indicate "no pain" and 10 as the top number to indicate "worst possible pain" and containing small horizontal markers every $10 \mathrm{~mm}$ on the line. The 6 facial expressions of the FPS, suggesting various pain intensities, were used to supplement the vertical NPRS. The bottom face (a smiling face) was accompanied by the number 0 ("no pain"), and the top face (a sad, tearful face) was accompanied by the number 10 ("worst possible pain"). Participants were asked to point only to a number, not a face, on the NPRS-FPS that best represented their current level of arm pain. The question posed to all participants rating their level of pain intensity

\section{Volume 6 Issue 12, December 2017}

\author{
www.ijsr.net
}

Licensed Under Creative Commons Attribution CC BY 


\section{International Journal of Science and Research (IJSR) \\ ISSN (Online): 2319-7064}

Index Copernicus Value (2016): 79.57 | Impact Factor (2015): 6.391

was as follows: "How much pain do you feel today? Please point to a number that best reflects your current level of heel pain."

At 6 months follow up patients rating 0 to 1 in the pain score chart was grouped as improved while those marking 02 or above were considered as non-responders.

All results were tabulated based on above differences. Statistical analyses was done using student $t$ test to find if there is any difference in improvement felt by patients between the two methods of treatment.

\section{Results}

Out of the 121 patients treated with one of the two methods, 18 patients did not follow up continually until 6 months for reasons not known. Among 18 who did not follow up, 11 ( 8 males and 3 females) were those treated by first method of conservative treatment, while remaining 7 (3 males and 4 females) were treated with second method. Of the follow up group up till 6 months, 53 (35 males, 18 females) underwent first method and 50 (37 males and 13 females) had undergone the second method making the total of 103 patients who actively took part and completed the study.

There was significant difference between the two methods of treatment in terms of betterment of pain and function based on evaluation of pain score questionnaire given to patients during the 6 months follow up (p 0.005). The heel pain subsided in $84.90 \%$ (33 males, 12 females) of cases treated with first method while only $52 \%$ (20 males, 6 females) cases improved with second method of treatment. Among the $15.09 \%$ of non-responders in method one treatment, 2 were males and 6 were females. Among the $48 \%$ of non-responders with method two of treatment, 17 were males and 7 were females.

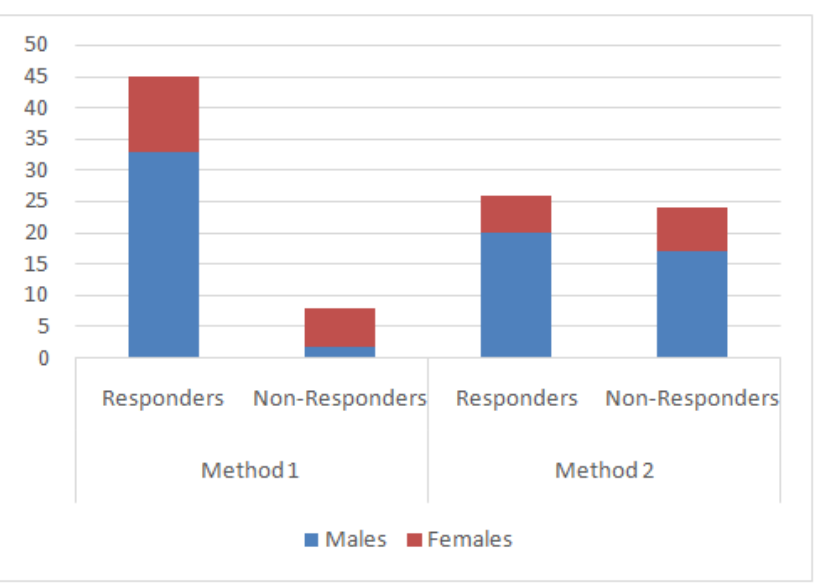

\section{Discussion}

Plantar fasciitis is a very common foot disorder and most often unilateral and idiopathic, having a multifactorial origin, and involving degeneration and inflammation of plantar fascia (18). Management of the idiopathic disorder with two different methods was tried in this study. The role of calcium and vitamin $\mathrm{D}$ in treatment of heel pain due to stress microfractures in calcaneus is well known (19-23). Vitamin D deficiency is mainly associated with weakness, pain of the arches, stress fractures and needs to be suspected and treated with vitamin $\mathrm{D}$ in patients presenting clinically as plantar fasciitis (23-25). Calcium supplementation is known to reduce or prevent tissue degenerative effects of the inflammatory disease, decrease osteoporosis and stress fractures of the foot, and promotes connective tissue regrowth $(19-23,26)$.

The role of soft foot wear using different materials is also well documented in literature. Shoes with longitudinal arch support can help decrease the pain associated with long periods of standing in patients with pes planus $(11,9$, 27). Similarly, shoes with thicker, well-cushioned midsoles made of high-density ethylene vinyl acetate is also known to decrease pain score to an extent (11).

In a study conducted in US in fifteen different centres for treatment of plantar fasciitis found that their improvement rates with prefabricated inserts were higher than those assigned to stretching only (15). Likewise it was noted that mechanical treatment with taping and orthoses is more effective than either anti-inflammatory or accommodative modalities (16). The custom-moulded semi rigid orthosis reduces fascial strain by supporting the first metatarsal bone and by controlling calcaneal position when in conjunction with a firm posterior counter shoe $(7,28-30)$.

Plantar fascia-stretching exercises like the Achilles tendon-stretching program have shown marked improvement in terms of pain, function, and satisfaction on a 2 year follow up questionnaire evaluation in a prospective observational trial $(11,14,27)$. Other stretching exercises which focus on intrinsic muscles of foot include Cross-friction massage above the plantar fascia, towelcurls, toe taps, and picking up marbles with the toes $(11,9,31,32)$. Physiotherapists subject patients to plantar fascia stretching exercises and to cold therapy (33, 34) while Orthosurgeons generally advise heat therapy. Fomentation of plantar fascia with hot water is known to promote healing by increasing the blood flow to the plantar fascia (3). There is also evidence of improvement in plantar fasciitis on conservative treatment with ice massage (34). Diet is rarely advised unless gout is suspected (9).

Although the treatment modalities would vary from a Family Practitioner, Physiotherapist and a Orthopaedician it has been known that early diagnosis and treatment leads to a shorter course of treatment and greater satisfaction among patients with plantar fasciitis with conservative therapies $(11,6,35)$

\section{Conclusion}

There is a definite role of calcium, vitamin D, soft footwear, prefabricated inserts, specific exercises, and hot water fomentation in the management of plantar fasciitis. The empirically advised vegetarian diet probably has a large role to play in patients taking a mixed diet and also raises a doubt whether these patients are subsequently 


\section{International Journal of Science and Research (IJSR) \\ ISSN (Online): 2319-7064}

Index Copernicus Value (2016): 79.57 | Impact Factor (2015): 6.391

going to develop gout or are there inflammatory substances in a non vegetarian high protein diet.

\section{Reference}

[1] Gudeman SD, Eisele SA, Heidt RS, Colosimo AJ, Stroupe AL. Treatment of plantar fasciitis by iontophoresis of $0.4 \%$ dexamethasone. A randomized, double-blind, placebo-controlled study. Am J Sports Med. 1997 Jun; 25(3):312-6.

[2] Deshpande MM, Patil C. Heel pain and phonophoresis. J Indian Med Assoc. 2010; 108(6):365-365.

[3] Goff JD, Crawford R. Diagnosis and treatment of plantar fasciitis. Am Fam Physician. 2011 Sep 15; 84(6):676-82.

[4] Riddle DL, Schappert SM. Volume of ambulatory care visits and patterns of care for patients diagnosed with plantar fasciitis: a national study of medical doctors. Foot Ankle Int. 2004 May; 25(5):303-10.

[5] Lemont H, Ammirati KM, Usen N. Plantar Fasciitis. J Am Podiatr Med Assoc [Internet]. 2003; 93(3):234-7. Available from: http://dx.doi.org/10.7547/87507315-93-3-234

[6] Singh D, Angel J, Bentley G, Trevino SG. Fortnightly review. Plantar fasciitis. BMJ. 1997 Jul 19; 315(7101):172-5.

[7] Kwong P, Kay D, Voner R, White M. Plantar fasciitis. Mechanics and pathomechanics of treatment. Clin Sports Med [Internet]. 1988 Jan;7(1):119-126. Available from: http://europepmc.org/abstract/MED/3044618

[8] Riddle DL, Pulisic M, Pidcoe P, Johnson RE. Risk factors for Plantar fasciitis: a matched case-control study. J Bone Joint Surg Am. 2003 May; 85-A (5):872-7.

[9] Roxas M. Plantar fasciitis: diagnosis and therapeutic considerations. Altern Med Rev J ClinTher. 2005 Jun; 10(2):83-93.

[10] Cornwall MW, McPoil TG. Plantar fasciitis: etiology and treatment. J Orthop Sports Phys Ther. 1999 Dec; 29(12):756-60.

[11] Young CC, Rutherford DS, Niedfeldt MW. Treatment of plantar fasciitis. Am Fam Physician. 2001 Feb 1; 63(3):467-74, 477-8.

[12] Neufeld SK, Cerrato R. Plantar fasciitis: evaluation and treatment. J Am AcadOrthop Surg. 2008 Jun; 16(6):338-46.

[13] Prichasuk S, Subhadrabandhu T. The relationship of pes planus and calcaneal spur to plantar heel pain. ClinOrthop. 1994 Sep ;( 306):192-6.

[14] Digiovanni BF, Nawoczenski DA, Malay DP, Graci PA, Williams TT, Wilding GE, et al. Plantar FasciaSpecific Stretching Exercise Improves Outcomes in Patients with Chronic Plantar Fasciitis. J Bone Jt Surg. 2006; 88(8):1775-81.

[15] Pfeffer G, Bacchetti P, Deland J, Lewis A, Anderson R, Davis W, et al. Comparison of custom and prefabricated orthoses in the initial treatment of proximal plantar fasciitis. Foot Ankle Int. 1999 Apr; 20(4):214-21.
[16] Lynch DM, Goforth WP, Martin JE, Odom RD, Preece CK, Kotter MW. Conservative treatment of plantar fasciitis. A prospective study. J Am Podiatr Med Assoc [Internet]. 1998; 88(8):375-80. Available from: http://dx.doi.org/10.7547/87507315-88-8-375

[17] Gill LH, Kiebzak GM. Outcome of nonsurgical treatment for plantar fasciitis. Foot Ankle Int. 1996 Sep; 17(9):527-32.

[18] SCHEPSIS AA, LEACH RE, GOUYCA J. Plantar Fasciitis: Etiology, Treatment, Surgical Results, and Review of the Literature. ClinOrthop [Internet]. 1991; 266. Available from: http://journals.lww.com/corr/Fulltext/1991/05000/Pl antar_Fasciitis_Etiology,

Treatment, Surgical.29.aspx

[19] Ruohola J-P, Laaksi I, Ylikomi T, Haataja R, Mattila VM, Sahi T, et al. Association Between Serum 25(OH)D Concentrations and Bone Stress Fractures in Finnish Young Men. J Bone Miner Res [Internet]. 2006 Sep 1; 21(9):1483-8. Available from: http://dx.doi.org/10.1359/jbmr.060607

[20] Kaye RA. Insufficiency stress fractures of the foot and ankle in postmenopausal women. Foot Ankle Int. 1998 Apr; 19(4):221-4.

[21] Kurosawa H, Nakasita K, Nakasita H, Sasaki S, Takeda S. Bilateral atraumatic avulsion fracture of the calcaneal tubercle in osteomalacia during fluoride therapy-case report. Am J Med. 1997; 102(1):35s - 9s.

[22] Knapp TP, Garrett WE. Stress fractures: general concepts. Clin Sports Med. 1997; 16(2):339-56.

[23] McClung JP, Karl JP. Vitamin D and stress fracture: the contribution of vitamin $\mathrm{D}$ receptor gene polymorphisms. Nutr Rev. 2010; 68(6):365-9.

[24] Paice EW, Hoffbrand BI. Nutritional osteomalacia presenting with plantar fasciitis. J Bone Joint Surg Br. 1987 Jan; 69(1):38-40.

[25] Danczak A. Aches and pains in primary care. Br J Gen Pract [Internet]. 2010 May 1; 60(574):374374. Available from: http://www.ncbi.nlm.nih.gov/pmc/articles/PMC285 8539/

[26] Meisner LF. Treatment for tissue degenerative inflammatory disease [Internet]. Google Patents; 1987. Available from: https://www.google.com/patents/US4647453

[27] Wolgin M, Cook C, Graham C, Mauldin D. Conservative treatment of plantar heel pain: longterm follow-up. Foot Ankle Int. 1994 Mar; 15(3):97-102.

[28] Seligman DA, Dawson DR. Customized heel pads and soft orthotics to treat heel pain and plantar fasciitis. Arch Phys Med Rehabil. 2003 Oct; 84(10):1564-7.

[29] Lee SY, McKeon P, Hertel J. Does the use of orthoses improve self-reported pain and function measures in patients with plantar fasciitis? A metaanalysis. Phys Ther Sport Off J Assoc Chart Physiother Sports Med. 2009 Feb; 10(1):12-8.

[30] Chia KKJ, Suresh S, Kuah A, Ong JLJ, Phua JMT, Seah AL. Comparative trial of the foot pressure patterns between corrective orthotics, formthotics, 


\section{International Journal of Science and Research (IJSR) \\ ISSN (Online): 2319-7064}

Index Copernicus Value (2016): 79.57 | Impact Factor (2015): 6.391

bone spur pads and flat insoles in patients with chronic plantar fasciitis. Ann Acad Med Singapore. 2009 Oct; 38(10):869-75.

[31] Niedfeldt MW. A friend told me my heel pain is probably plantar fasciitis. What is this condition, and how is it treated? Health News Walth Mass. 2002 Jun; 8(6):12.

[32] Hyland MR, Webber-Gaffney A, Cohen L, Lichtman PTSW. Randomized controlled trial of calcaneal taping, sham taping, and plantar fascia stretching for the short-term management of plantar heel pain. J Orthop Sports Phys Ther. 2006 Jun; 36(6):364-71.

[33] Gill LH, Kiebzak GM. Outcome of nonsurgical treatment for plantar fasciitis. Foot Ankle Int. 1996 Sep; 17(9):527-32.

[34] Leach RE, Seavey MS, Salter DK. Results of surgery in athletes with plantar fasciitis. Foot Ankle. 1986 Dec; 7(3):156-61.

[35] Buchbinder R. Clinical practice. Plantar fasciitis. N Engl J Med. 2004 May 20; 350(21):2159-66.

[36] 36.Li-ling Chuang, Ching-yi Wu, Keh-chung Lin, Ching-ju Hsieh. Relative and Absolute Reliability of a Vertical Numerical Pain Rating Scale Supplemented with a Faces Pain Scale After Stroke. 2014 Jan; DOI: 10.2522/ptj.20120422

Volume 6 Issue 12, December 2017

www.ijsr.net 